\title{
Characterization of GLPG0492, a selective androgen receptor modulator, in a mouse model of hindlimb immobilization
}

\author{
Roland Blanqué, Liên Lepescheux, Marielle Auberval, Dominique Minet, Didier Merciris, Céline Cottereaux, \\ Philippe Clément-Lacroix*, Philippe Delerive and Florence Namour
}

\begin{abstract}
Background: Muscle wasting is a hallmark of many chronic conditions but also of aging and results in a progressive functional decline leading ultimately to disability. Androgens, such as testosterone were proposed as therapy to counteract muscle atrophy. However, this treatment is associated with potential cardiovascular and prostate cancer risks and therefore not acceptable for long-term treatment. Selective Androgen receptor modulators (SARM) are androgen receptor ligands that induce muscle anabolism while having reduced effects in reproductive tissues. Therefore, they represent an alternative to testosterone therapy. Our objective was to demonstrate the activity of SARM molecule (GLPG0492) on a immobilization muscle atrophy mouse model as compared to testosterone propionate (TP) and to identify putative biomarkers in the plasma compartment that might be related to muscle function and potentially translated into the clinical space.
\end{abstract}

Methods: GLPG0492, a non-steroidal SARM, was evaluated and compared to TP in a mouse model of hindlimb immobilization.

Results: GLPG0492 treatment partially prevents immobilization-induced muscle atrophy with a trend to promote muscle fiber hypertrophy in a dose-dependent manner. Interestingly, GLPG0492 was found as efficacious as TP at reducing muscle loss while sparing reproductive tissues. Furthermore, gene expression studies performed on tibialis samples revealed that both GLPG0492 and TP were slowing down muscle loss by negatively interfering with major signaling pathways controlling muscle mass homeostasis. Finally, metabolomic profiling experiments using ${ }^{1} \mathrm{H}-\mathrm{NMR}$ led to the identification of a plasma GLPG0492 signature linked to the modulation of cellular bioenergetic processes.

Conclusions: Taken together, these results unveil the potential of GLPG0492, a non-steroidal SARM, as treatment for, at least, musculo-skeletal atrophy consecutive to coma, paralysis, or limb immobilization.

Keywords: Selective androgen receptor modulator, Immobilization, Muscle wasting, Anabolism

\section{Background}

Maintenance of skeletal muscle mass is mainly achieved by a homeostatic balance between muscle regeneration, protein synthesis and protein degradation. This tight balance is significantly altered during aging, leading to muscle wasting coupled to a decline in function over time named sarcopenia [1]. In addition, skeletal muscle atrophy occurs in many chronic conditions such as cancer cachexia, sepsis, diabetes, renal failure and arthritis [2,3]. Mechanistic

* Correspondence: philippe.clement-lacroixl@glpg.com

GALAPAGOS SASU, 102 Avenue Gaston Roussel, 93230 Romainville, France studies performed in rodent models of muscle atrophy as well as in patients revealed that atrophy is an active process regulated by specific signaling pathways and transcriptional programs (See [4] for review). Clusters of genes similarly up or down-regulated in the atrophied muscle under various conditions are referred as atrogenes [5]. The rapid induction of the muscle-specific ubiquitin ligases, MAFbx/atrogin-1 and muscle ring finger 1 (MurF1) gene expression in response to atrophic stimuli revealed the activation of protein catabolism via the Ubiquitin (Ub) $26 \mathrm{~S}$ proteasomal pathway as an early event leading to 
muscle atrophy [6-8]. Furthermore, mice deficient for Atrogin-1 or MurF1 were shown to be resistant to some extent to denervation induced atrophy [6]. Finally, Atrogin-1 and MurF1 were reported to be involved in the degradation of both regulatory and structural proteins including MyoD, Calcineurin A and myosin, respectively [9-12]. In addition to the Ubiquitin-proteasome pathway, autophagy has also been shown as a major signal activated at the transcriptional level and leads to protein catabolism (See [4] for review). The lysosome proteases, Cathepsin-L and LC3-II were reported to be increased in rodent models of muscle atrophy $[13,14]$. FoxOs have been identified as key transcription factors at the crossroads of both protein breakdown via the regulation of Atrogin-1 and MurF1 gene transcription $[8,15]$ and protein synthesis via the regulation of 4EBP1 and the subsequent inhibition of the mTOR signaling pathway [16]. Disruption of the subtle balance between protein synthesis and degradation during muscle atrophy involves the suppression of bioenergetic pathways associated to mitochondrial functions and controlled by PGC- $1 \alpha$ whose expression is sharply reduced in various models of muscle wasting [17-19].

Despite our growing understanding of the molecular mechanisms controlling muscle atrophy, there is still an unmet need for therapies that prevent or reverse muscle atrophy resulting into a significant improvement of physical function in patients. A large number of studies have established the beneficial impact of androgen treatment on both muscle mass and strength [20,21]. Androgens control a broad spectrum of physiological processes mainly via the nuclear androgen receptor (AR), a member of the nuclear receptor super-family [22]. However, treatment with androgens such as testosterone is associated with potential cardiovascular and prostate cancer risks [23]. Furthermore, alteration of circulating levels of androgens or modulation in receptor function lead to multiple disorders such as hypogonadism, muscle wasting, cachexia, osteoporosis, loss of reproductive functions and prostate cancers [23]. Selective androgen receptor modulator (SARM), synthetic compounds designed to demonstrate tissue-specific action for muscle and bone represent an alternative to testosterone therapy (See $[24,25]$ for review). We recently identified GLPG0492 as a non-steroidal SARM [26]. This molecule displays an excellent selectivity profile ( $>500$-fold in binding assays) versus members of the steroid receptor family and behaves as a partial AR agonist in cell-based assays [26]. GLPG0492 has been previously tested in a standard castrated male rodent model in which it demonstrated after oral dosing robust anabolic activity on levator ani (LA) muscle comparable to testosterone propionate, but dissociated from the androgenic activity on ventral prostate. The dose displaying $50 \%$ activity on LA was $0.75 \mathrm{mg} / \mathrm{kg} /$ day, while at the maximum $30 \%$ activity can be achieved on prostate at the highest dose tested [27].
So, GLPG0492 has demonstrated a robust selectivity for muscle versus prostate, as SARM [26,27].

To determine the therapeutic potential of GLPG0492 for muscle wasting-associated diseases, we evaluated this compound in a mouse model of hindlimb immobilization and compared its effects to testosterone propionate as reference. In this model, GLPG0492 attenuated the loss of muscle mass induced by immobilization by reducing, at least in part, fiber atrophy. Furthermore, gene expression studies revealed that GLPG0492 negatively antagonized transcriptional programs induced by immobilization. Finally we look for a metabolomic signature which might be considered as a bona fide biomarker of target engagement in future clinical studies. Taken together, these results revealed the potential of GLPG0492 as treatment for disuse (e.g. coma, paralysis, hospitalization, limb immobilization).

\section{Methods}

\section{Reagents}

GLPG0492 was synthesized by the medicinal chemistry department at Galapagos and was determined to be $>99 \%$ pure by HPLC and/or NMR analysis [26]. Testosterone proprionate was purchased from Sigma (France). Dosing solutions of GLPG0492 and TP were prepared as solutions in a vehicle of 5\% Ethanol and 95\% Corn oil.

\section{Animal studies}

Experimental protocols were approved by the Galapagos Institutional Animal Care and Use Committee. Male BALB/ cj mice (10 weeks old; $n=10$ /group, Janvier Labs) maintained on a standard chow diet, were subjected to unilateral hindlimb plaster casting (day 0) as previously described [28]. Intact or immobilized mice were treated for 7 days with increasing doses of GLPG0492 (0.3, 3 and $10 \mathrm{mg} / \mathrm{kg} / \mathrm{d})$ or testosterone-propionate (TP: $1 \mathrm{mg} / \mathrm{kg} / \mathrm{d})$ or vehicle $(5 \%$ Ethanol/95\% Corn oil) by subcutaneous administration. At the end of the treatment period ( $5 \mathrm{~h}$ after the last dose), mice were sacrificed by decapitation and blood was recovered for serum preparation. Gastrocnemius and tibialis from both immobilized and contralateral legs were collected, weighed, and snap-frozen in liquid nitrogen.

\section{Bio-analysis}

Blood samples were collected in lithium heparinate-containing vials in order to prepare serum samples. Serum testosterone levels were evaluated at day 7 in each group using a RIA kit (Orion Diagnostica, Finland). In addition, circulating levels of GLPG0492 were quantified at steady-state at 3 or $5 \mathrm{~h}$ post-dose by LC-MS/MS in Galapagos bioanalytical department.

\section{RNA analysis}

Total RNA was extracted from tibialis using Qiagen RNA extraction kits following manufacturer's instructions. Total 
RNA was treated with DNase I (Ambion Inc., Austin, Texas, USA) at $37^{\circ} \mathrm{C}$ for 30 minutes, followed by inactivation at $75^{\circ} \mathrm{C}$ for 5 minutes. Real time quantitative PCR (RT-QPCR) assays were performed using an Applied Biosystems ViiA7 sequence detector. Total RNA $(1 \mu \mathrm{g})$ was reverse transcribed with random hexamers using Taqman reversetranscription reagents kit (Applied Biosystems) following the manufacturer's protocol. Gene expression of Atrogin-1, MurF1, IGF1, LC3, FoxO1, IL1 $\beta$, Myogenin, and PGC1 $\alpha$ and PGC1 $\alpha 4$ levels were determined by Sybr green assays [29]. Atrogin-1, MurF1, IGF1, LC3, FoxO1, IL1 $\beta$, Myogenin, PGC1 $\alpha, \mathrm{PGC} 1 \alpha 4$ isoform were detected using QuantiTect Primer Assays (Qiagen) while PGC1 $\alpha 4$ isoform was detected using forward and reverse primers describe by Ruas and coworkers [30]. GAPDH transcript was used as an internal control to normalize the variations for RNA amounts. Gene expression levels are expressed relative to GAPDH mRNA levels. All the results presented are expressed as mean \pm S.E.M. All the primers used in this study and $\mathrm{Ct}$ values are available upon request.

\section{Tissue weighing and fiber cross-sectional area (FCSA) determination}

At sacrifice, tibialis and prostate were collected and weighed. Muscles were subsequently snap-frozen in liquid nitrogen. Cryo-sections (10 $\mu \mathrm{m}$ thick) were prepared from the mid-gastrocnemius using a cryostat (Microm) and fixed in formalin for one minute prior assayed with a double immunochemistry IHC as following: sections were probed simultaneously for 30 minutes with a mouse antiMyosin light chain (Clone NOQ, Abcam) and a rabbit anti-laminin antibody using an autostainer (Dako). Secondary antibodies were anti-mouse-fluorescein and antirabbit-dye light, respectively. Laminin IHC provided a fluorescent staining of the border of all fibers and myosin light-chain IHC gave a fluorescent stain of slow-twitch fibers. Consequently, the fibers only immunostained for laminin and not for myosin light chain correspond to the fast-twitch fibers. Histomorphometric analyses were performed using a fluorescent microscope (Objective 20, Olympus). Two series of images were recorded from two representative areas containing either fast-twitch only or both slow and fast-twitch fibers. Morphometric analyses were performed using the imaging software system (Sisn'Com, France). For the evaluation of FCSA and fibertype distribution, all fibers in each muscle section were analyzed. For FCSA, fibers were gathered in different groups according to their range size, and each group was expressed as a percentage of the total fiber number.

\section{${ }^{1} \mathrm{H}-\mathrm{NMR}$ metabolic profiling}

Serum samples (obtained at necropsy 5 h post last dose) were mixed with an equal volume of $3 / 2$ chloroform-D/ Methanol-D4. Following incubation, each sample was centrifuged at 6,000 rpm for 10 minutes. The upper layer was recovered and mixed with an internal standard solution provided by Chenomx (Edmonton, Canada). NMR spectra were acquired on a Varian INOVA $800 \mathrm{MHz}$ NMR spectrometer equipped with a Z-gradient $\mathrm{HCN} 5 \mathrm{~mm}$ cold-probe. The pulse sequence used was 1D-noesy with a $990 \mathrm{~ms}$ pre-saturation on water and a $4 \mathrm{~s}$ acquisition time. Spectra were collected with 416 transients and 4 steadystate scans at $298 \mathrm{~K}$. Spectra were processed and analyzed using Chenomx NMR suite 7.1.

\section{Statistical analysis}

Results are shown as mean \pm S.E.M. Data were analyzed by ANOVA followed by Dunnett's multiple comparison tests. Differences with $\mathrm{p}<0.05$ were considered to be statistically significant. For FCSA distribution, the relationship between treatment and FCSA distribution has been displayed in a contingency table. The differences between the frequencies of FCSA distribution were tested by Chi-square test. In addition, ANOVA followed by Dunnett's multiple comparison tests have been performed for each cluster of distribution.

\section{Results \& discussion}

Skeletal muscle atrophy can be experimentally induced in rodents using different approaches such as the denervation [31], tail suspension [32] or cast immobilization [33]. The anabolic properties of the recently identified SARM, GLPG0492, were evaluated in the adapted mouse model of hindlimb immobilization as described by Okamato and coworkers [28]. In this model, mice are subjected to unilateral hindlimb plaster casting. As expected, hindlimb immobilization for 7 days resulted in a significant loss in muscle mass $(-21 \%, \mathrm{p}<0.001)$ compared to intact animals (Figure 1A). TP treatment completely prevented muscle loss at day 7 in line with previous reports [34,35]. Interestingly, GLPG0492 dose-dependently reduced immobilization-induced gastrocnemius atrophy with a maximal significant effect observed between 3 and $10 \mathrm{mg} / \mathrm{kg} / \mathrm{d}$. After 7 days of treatment, TP induced a small but significant increase in gastrocnemius weight in the contralateral leg as compared to intact animals, demonstrating its anabolic properties (Figure 1B). A similar dose-response was observed in GLPG0492-treated mice although the difference was found statistically significant only at dose $3 \mathrm{mg} / \mathrm{kg} / \mathrm{d}$ (Figure 1B). Similar results were obtained in female mice (data not shown). Dose-dependent effects of GLPG0492 in this model are in line with its plasma exposure at steady state (Table 1). These results indicate that GLPG0492, similarly to TP, is able to reduce skeletal muscle atrophy in the hindlimb immobilization model in a dose-dependent manner. It is noteworthy that GLPG0492 efficacy was achieved without significant alterations in circulating testosterone 

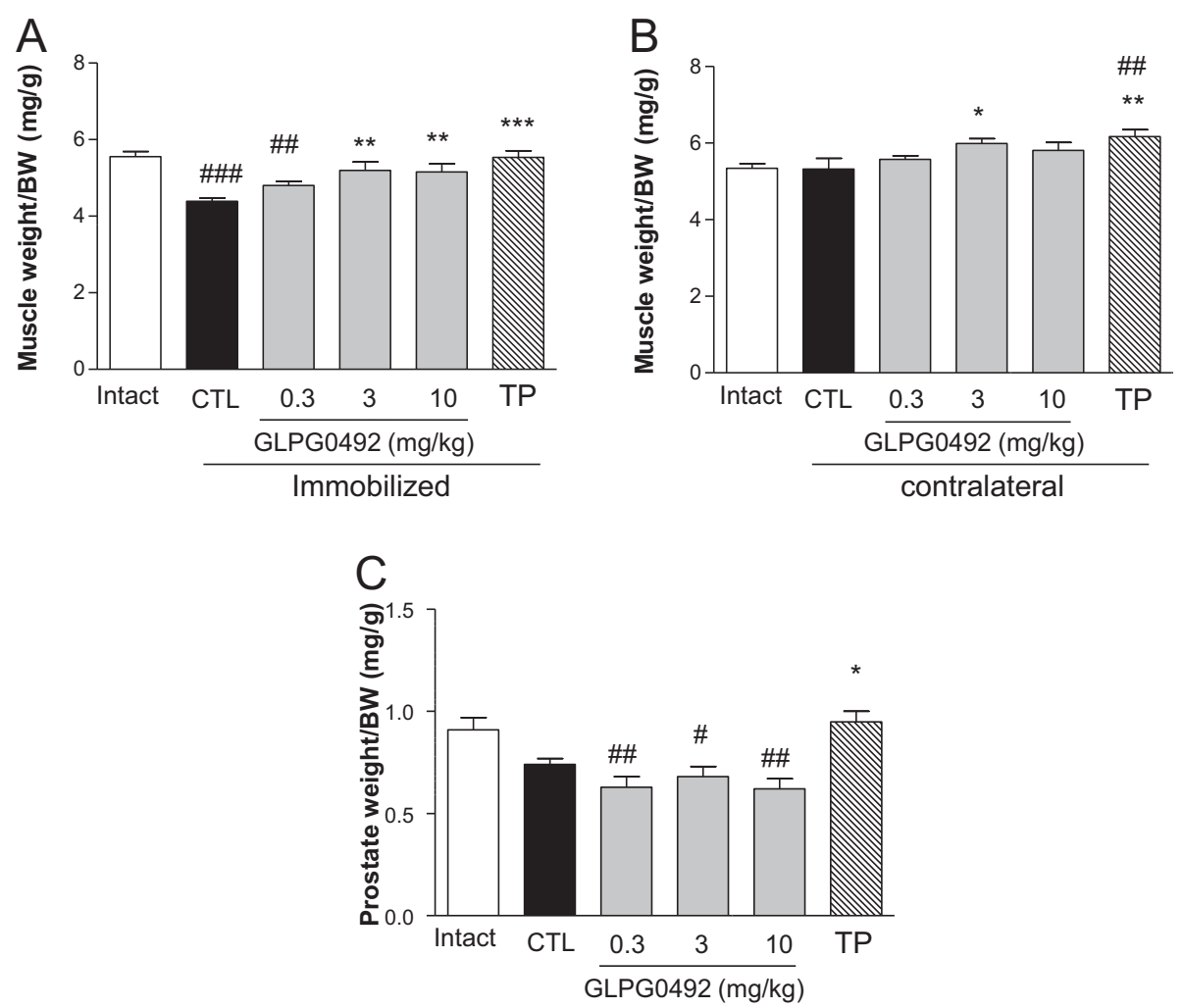

Figure 1 GLPG0492 reversed immobilization-induced muscle atrophy in a dose-dependent manner. Normalized gastrocnemius weight from both immobilized (Panel A) and contralateral (Panel B) legs was assessed at day 7 in intact or immobilized mice receiving increasing doses of GLPG0492 (0.3, 3, $10 \mathrm{mg} / \mathrm{kg} /$ day) or TP (1 mg/kg/day) or CTL immobilized (ethanol/corn oil, 5/95 v/v). Panel C: Normalized prostate weight at day 7, from immobilized mice receiving increasing doses of GLPG0492 $(0.3,3,10 \mathrm{mg} / \mathrm{kg} / \mathrm{day})$ or TP or CTL vehicle $(\mathrm{n}=10$ per group; \#p $<0.05$, \#\#p $<0.01$, \#\#\#p $<0.001$ vs. Intact (white bar); ${ }^{*} p<0.05,{ }^{* *} p<0.01,{ }^{* * *} p<0.001$ vs. CTL immobilized (black bar)).

levels (Table 2), nor increasing of prostate weight in contrast to TP as compared to immobilized control group (Figure 1C). Finally if body weight loss is observed between intact group and the whole of immobilized groups at day 7, nor TP, neither GLPG0492 treatments are able to counteract this loss (Table 2).

Having established the anabolic properties of GLPG0492 in an experimental model of muscle loss, we next determined its influence on muscle fibers atrophy. As expected, 7 days of immobilization led to a reduction of both slow

Table 1 Plasma GLPG0492 levels in male mice at steady-state ( $\mathrm{n}=\mathbf{5}$ per group)

\begin{tabular}{lcc}
\hline $\begin{array}{l}\text { Dose } \\
(\mathbf{m g} / \mathbf{k g} / \mathbf{d})\end{array}$ & $\begin{array}{c}\text { Time } \\
\text { point }(\mathbf{h r})\end{array}$ & $\begin{array}{c}\text { GLPG0492 } \\
\text { mean } \pm \text { SEM }(\mathbf{n g} / \mathbf{m L})\end{array}$ \\
\hline 0.3 & 3 & $8.62 \pm 2.33$ \\
& 5 & $4.78 \pm 0.46$ \\
3 & 3 & $78.8 \pm 9.06$ \\
& 5 & $58.0 \pm 7.45$ \\
10 & 3 & $184.0 \pm 15.4$ \\
& 5 & $512.0 \pm 324.5$ \\
\hline
\end{tabular}

(indicated by a red star) and fast-twitch (indicated by a white star) fibers diameter as demonstrated by histomorphometric analysis (Figure 2A). These results are in line with previously published reports [28,36,37]. Fibers atrophy was similarly modulated by both GLPG0492 (at $10 \mathrm{~m}$ / $\mathrm{kg} / \mathrm{d}$ ) and TP treatments (Figure 2B). Effects obtained with GLPG0492 tended to be dose-dependent (Figure 2B). GLPG0492 and TP treatments both modify mean FCSA and distribution of muscle fibers. Moreover FCSA from TP and GLPG0492-treated groups were not significantly different, even though GLPG0492 seems more active on slow fibers (Figure 2B \& 2C).

These results indicate that GLPG0492 partially prevents immobilization-induced muscle loss by, at least in part, limiting muscle fiber atrophy. It is noteworthy that both GLPG0492 and TP affect similarly both slow and fast twitch muscle fiber in line with previous studies performed in young men [38].

Since skeletal muscle atrophy has clearly been linked to the activation of various transcriptional programs (See [4] for review), we next determined the influence of both GLPG0492 and TP on the expression of key genes previously identified in experimentally-induced muscle atrophy 
Table 2 Serum testosterone levels and body weight evolution in male mice treated for 7 days with increasing doses of GLPG0492 and TP

\begin{tabular}{lcccc}
\hline & Testosterone (nM) & Body weight day 0 (gr) & Body weight day 7 (gr) & \% BW increase (d7-d0) \\
\hline Intact & $2.4 \pm 0.6$ & $24.3 \pm 0.3$ & $25.5 \pm 0.3$ & $+5.0 \%$ \\
CTL & $1.7 \pm 0.3$ & $24.2 \pm 0.4$ & $22.5 \pm 0.5^{\# \# \#}$ & $-6.8 \%$ \\
GLPG0492 $0.3 \mathrm{mg} / \mathrm{kg} / \mathrm{d}$ & $1.9 \pm 0.6$ & $24.2 \pm 0.2$ & $23.7 \pm 0.3^{\# \# \#}$ & $-1.9 \%$ \\
GLPG0492 $3 \mathrm{mg} / \mathrm{kg} / \mathrm{d}$ & $2.2 \pm 0.8$ & $23.6 \pm 0.4$ & $22.9 \pm 0.3^{\# \# \#}$ & $-2.3 \%$ \\
GLPG0492 $10 \mathrm{mg} / \mathrm{kg} / \mathrm{d}$ & $1.7 \pm 0.6$ & $23.8 \pm 0.2$ & $23.3 \pm 0.3^{\# \# \#}$ & $-2.1 \%$ \\
TP 1 mg/kg/d & $3.3 \pm 0.5$ & $23.8 \pm 0.3$ & $23.4 \pm 0.4^{\# \# \#}$ & $-1.6 \%$ \\
\hline
\end{tabular}

Data ( $\mathrm{n}=10$ per group) are expressed as mean \pm SEM. ${ }^{\# \# \#} \mathrm{p}<0.001$ vs. Intact (day7).

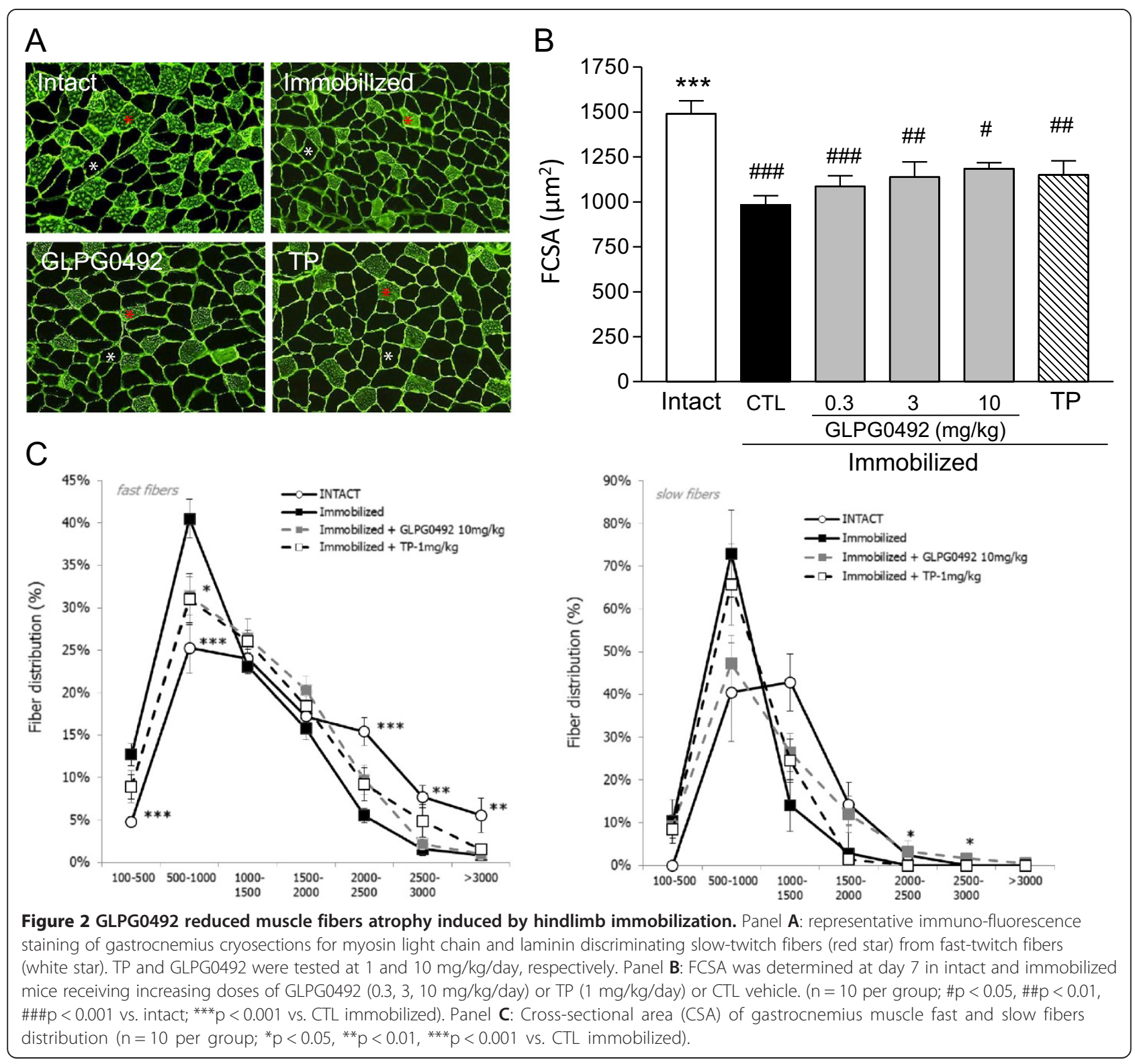


$[5,8,36,39]$. Most of the transcriptional changes linked to atrophy were found to mainly occur early on in the early phases (between day 2 and day 7) in both rodent and human studies $[5,17,28,36,40]$. Gene expression studies were performed on tibialis, one of the two intermediary twitch muscles collected. As expected, casting resulted in a significant induction of the expression of the muscle-specific ubiquitin ligases, Atrogin-1 and MurF1 (Figure 3a). Surprisingly, MurF1, but not Atrogin-1, expression was significantly inhibited in response to both GLPG0492 and TP treatments (Figure 3a). Expression of FoxO1, a transcription factor, controlling atrogene expression and maintaining the atrophied state $[8,15]$, was also found up-regulated after 7 days of immobilization. This gene induction was significantly attenuated in response to both GLPG0492 and TP treatments. Similarly Myogenin, a gene encoding a transcription factor known to be increased in atrophied muscles $[5,41]$, was also up-regulated after 7 days of immobilization and was also repressed by both GLPG0492 and TP treatments (Figure 3b). Cytokines including TNF $\alpha$ and IL1 $\beta$ have been shown to be involved in the pathogenesis of muscle wasting [42]. Here, we found a very significant induction of IL1 $\beta$ expression (9fold) in immobilized versus intact animals in line with previous findings [39]. Remarkably, this induction was abolished by GLPG0492 and TP treatments. Finally, PGC- $1 \alpha$ mRNA levels were found to be modestly reduced in response to 7 days of immobilization (Figure 3B). PGC- $1 \alpha$ is a transcriptional co-activator that controls the expression of genes involved in oxidative metabolism and causes many of the changes associated with endurance training, including mitochondrial biogenesis, fiber-type switching, stimulation of fatty acid oxidation, angiogenesis and resistance to muscle atrophy $[43,19]$. So, these results are somehow in contrast with previous reports describing a profound suppression of PGC-1 $\alpha$ expression [5,19,39]. This discrepancy might be explained by the different kinetic of analysis. Indeed, PGC-1 $\alpha$ gene suppression seems to reach its peak after 2 to 3 days of immobilization [5]. In addition, it has been recently described that PGC- $1 \alpha$ plays a role in atrophy through the alternative splice variant called alpha-4 [30]. Our results shown that expression of PCG- $1 \alpha 4$ variant was not regulated by immobilization at day 7. It is noteworthy that gene regulations of the two PGC- $1 \alpha$ splice variants, in our model, are small in term of fold induction Nevertheless, the in PGC- $1 \alpha$ expression was significantly increased whereas $\mathrm{PGC} 1 \alpha 4$ is significantly decreased by GLPG0492 and TP treatments (Figure 3b). Taken together, these results suggest that GLPG0492 prevents muscle atrophy in this model by, at least in part, negatively interfering with different transcriptional programs related to muscle wasting.

Since skeletal muscle plays a key role in metabolic and energy homeostasis and since limb immobilization has been shown to profoundly affect bioenergetic pathways linked to mitochondrial function [17], we next performed a focused metabolomic analysis using ${ }^{1} \mathrm{H}-\mathrm{NMR}$ to capture these metabolic changes in the blood compartment and to determine whether GLPG0492 treatment may to some extent affect these alterations of the metabolome. Furthermore, identified metabolites significantly modulated in blood in response to GLPG0492 treatment might be considered as potential biomarkers of GLPG0492 during clinical development. Using ${ }^{1} \mathrm{H}$ NMR, 40 metabolites could be identified and precisely quantified within these samples (Table 3). The BCAAs are among the nine essential amino acids for humans, accounting for $35 \%$ of the essential amino acids in muscle proteins and $40 \%$ of the preformed amino acids required by mammals. Although it has been reported that muscle protein synthesis significantly declined during the first $6 \mathrm{~h}$ of immobilization (40), it has also been shown that immobilization of hindlimb by cast fixation for $1 \mathrm{~d}$ increased muscle protein breakdown [44]. Here, our hindlimb immobilization model led to a notable, but non-significant reduction in a number of circulating amino acids including the so-called branched-chain amino acids (BCAA: isoleucine, leucine and valine). BCAA have been shown to inhibit proteolysis in skeletal muscle $[45,46]$. These amino acids provide the amino groups required for synthesis of glutamine and alanine. Protein degradation in skeletal muscle results in the release of amino acids, particularly alanine. But alanine is channeled to the liver for gluconeogenesis and APP synthesis, and ALT activity is increased during immobilization, which could explain the reduced plasma alanine concentration in immobilized animals [47]. In addition, urocanate, a product derived from histidine breakdown, was significantly increased in serum samples from immobilized mice (Table 3).

As in our study, increased of atrogin-1 and MuRF1 proteins have been reported in hindlimb suspension rat model. L-leucine and the leucine metabolite $\beta$-hydroxy- $\beta$ methylbutyrate (Ca-HMB) have been reported to attenuate the increase in atrogin- 1 and MuRF1 proteins in hindlimb suspension rat model [48]. Another recent paper suggest that leucine, could down regulate the MurF1 protein in mouse cachexia model [49]. Nevertheless, in our study, modulation of BCAAs, especially leucine, by GLPG0492 is not strong enough to explain the significant gene regulation of MurF1. In fine, GLPG0492 treatment for 7 days did not significantly alter these changes in amino-acids levels with one exception being glutamine (Figure 4; Table 3). Glutamine has been shown to stimulate protein synthesis and to inhibit protein catabolism in skeletal muscle in vitro and in vivo [47].

By contrast, GLPG0492 treatment led to a significant elevation in tricarboxylic acid (TCA) cycle intermediates such as pyruvate, citrate, fumarate and succinate to a 


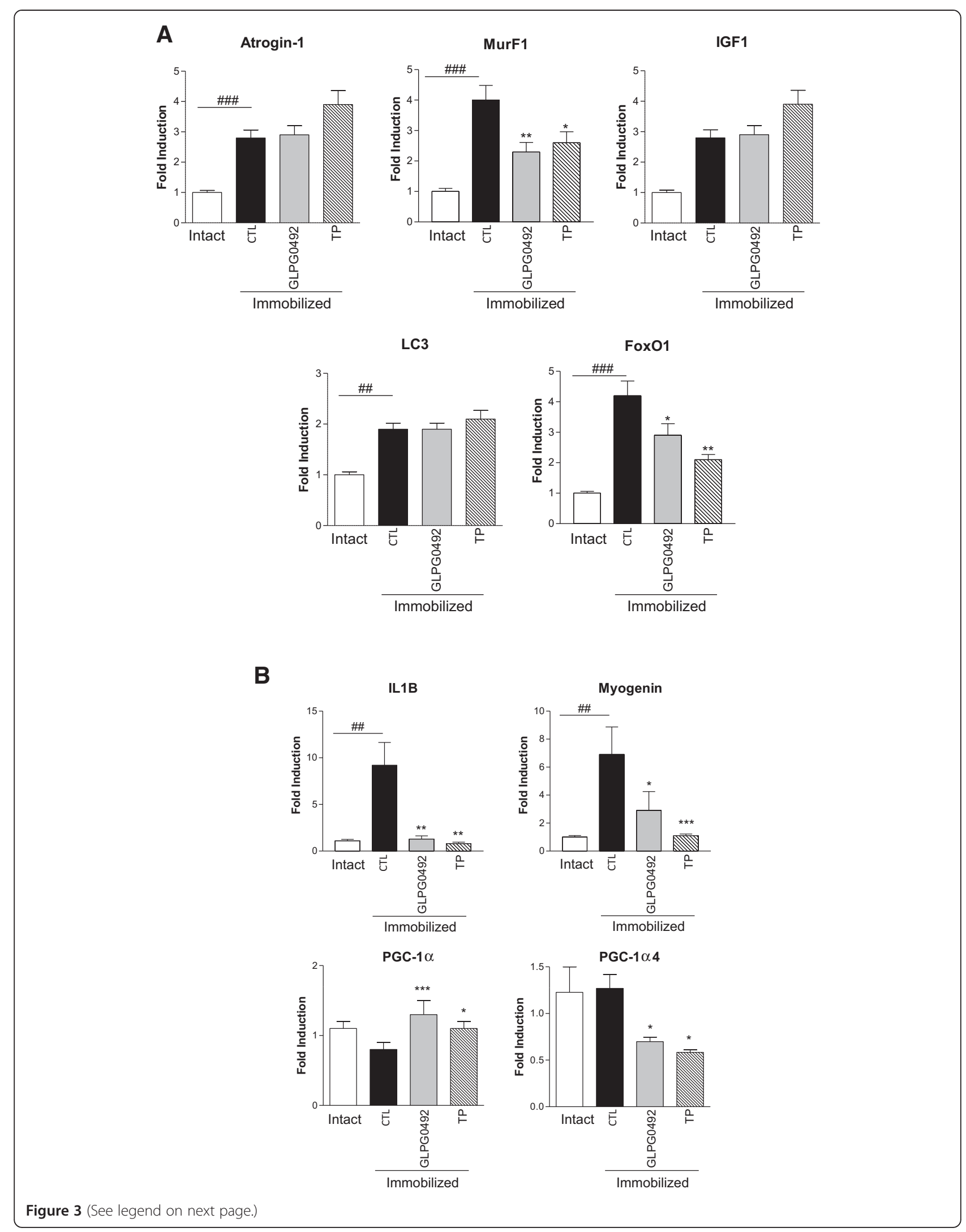


lesser extent (non-significant, $\mathrm{p}=0.054$ ) (Table 3; Figure 4). These TCA cycle intermediates were found as part of a metabolic signature of exercise in human plasma [50] and clearly point to a modulation of cellular bioenergetic processes linked to mitochondrial function. Moreover, ketone bodies such as 3-hydroxybutyrate, acetate and acetone were found also to be increased in response to our SARM. Interestingly, Vega and coworkers reported a similar increase in 3-hydroxybutyrate in adult men in response to a short-term administration of oxandrolone, a synthetic testosterone derivative [51]. These authors suggested that oxandolone induced hepatic ketogenesis. Additional studies will be required to determine whether GLPG0492mediated 3-hydroxybutyrate elevation in this hindlimb immobilization model is occurring through a similar mechanism. Finally, O-acetylcarnitine levels were doubled in response to GLPG0492. This might reflect an increase in fatty acid oxidation. Interestingly, plasma acetylcarnitines were identified as exercise-related biomarkers and to be essentially derived from skeletal muscle [52]. Taken together, results from the focused metabolomic study led to the identification of GLPG0492-specific metabolomic signature in the hindlimb immobilization model.

Our results are in accordance with several studies in rodents suggesting that muscle atrophy results from a large increase in proteolysis and an increased oxidative stress. Unfortunately, little information is available about the influence of immobilization on markers of muscle protein breakdown and oxidative stress in humans.

Results of these investigations indicate that GLPG0492, a non-steroidal SARM, is able to significantly reduce muscle atrophy in a mouse hindlimb immobilization model. These protective effects were dose-dependent, and achieved without significant alteration in serum testosterone levels, neither prostate weight (Figure $1 \mathrm{C}$ and Table 2). Moreover, the magnitude of the observed effects on muscle was comparable to the impact of TP. Muscle anabolic activities of SARM and testosterone are well-established in man $[20,21,53,54]$ and confirm in our model with significant increase of normalized prostate weight by TP. The molecular mechanisms by which AR ligands promote anabolism in skeletal muscle are very diverse and are still a matter of debate (See [54] for review). Androgens are believed to affect muscle mass by regulating protein synthesis, reducing protein breakdown, modulating myogenic differentiation and by interfering with key signaling pathways involved in skeletal muscle homeostasis [54]. These effects are mainly mediated by the AR. Chambon and colleagues demonstrated that the anabolic effects of androgens are transduced in limb muscles by the AR expressed in myocytes but also by satellite cells and myofibroblasts $[55,56]$. Moreover, this group reported a significant impact of AR gene deletion in myocytes on FCSA in both fast and intermediary-twitch muscles via a regulation of IGF-IEa production. In addition, myofibril organization was found to be disrupted in muscle-specific AR-deficient mice $[55,56]$. On the other hand, McLean and coworkers reported the characterization of AR total knock-out mice [57]. Male ARKO mice displayed a significantly reduced skeletal mass which could not be linked to a modulation of IGF-1 signaling [57]. In this report, transcriptomic analysis suggested that androgens regulate muscle mass via the control of muscle commitment and proliferation [57]. These effects might be explained, at least in part, by the AR-dependent regulation of ornithine decarboxylase, which regulates both myoblast proliferation and delays differentiation as demonstrated by a reduced myogenin expression [58]. In this model of hindlimb immobilization, we showed that both TP and GLPG0492 were able to prevent muscle atrophy by down-regulating key transcriptional programs induced by muscle disuse (Figure 3) [4]. Gene expression studies revealed the complex interplay between AR-dependent signaling pathways (See [50] for review). Interestingly, we did not observe any regulation of IGF-1Ea gene expression (Figure 3A). By contrast, myogenin expression which was significantly increased following immobilization in line with previous studies $[5,39]$, was completely suppressed in response to both GLPG0492 and TP treatments suggesting a potential impact on myoblast differentiation [58]. As previously described by Caron and coworkers in the immobilized mouse model, the induction of the muscle-specific ubiquitin ligases, MurF1 and Atrogin-1 is a hallmark of the atrophied state $[6,7,36]$. Surprisingly, both GLPG0492 and TP were found to inhibit immobilization-induced MurF1 but not Atrogin-1 expression (Figure 3). This selective regulation of these ubiquitin ligases is reminiscent of the phenotype of the muscle-specific IKK $\beta$ transgenic mice [59]. Overexpression of IKK $\beta$ in the muscle leads to severe muscle wasting due to MurF1 but not Atrogin-1 gene induction [59]. The role of NFkB signaling in muscle atrophy was independently confirmed by Hunter and colleagues $[60,61]$. Since AR has been shown to negatively interfering with $\mathrm{NF \kappa B}$ signaling pathway [60], it is tempting to speculate that both GLPG0492 and TP inhibit MurF1 expression via this mechanism. Further studies are required to fully 
Table 3 List of metabolites identified by ${ }^{1} \mathrm{H}-\mathrm{NMR}$ analysis of serum samples from intact or immobilized mice after 7 days of treatment with GLPG0492 (10 mg/kg/d) or CTL

\begin{tabular}{|c|c|c|c|c|c|c|c|c|}
\hline & & & & & & & & \\
\hline & Mean & SEM & & CTL & & & SLPGO & \\
\hline & & & Mean & SEM & p-value & Mean & SEM & $p$-value \\
\hline 3-Hydroxybutyrate & 239 & 46 & 184 & 25 & & 1207 & 302 & ** \\
\hline Acetate & 542 & 92 & 460 & 6 & & 857 & 124 & * \\
\hline Acetone & 19 & 5 & 14 & 3 & & 54 & & * \\
\hline Alanine & 1977 & 156 & 1214 & 191 & \#\# & 1218 & 45 & \\
\hline Asparagine & 201 & 27 & 124 & 21 & $\#$ & 127 & 10 & \\
\hline Betaine & 142 & 32 & 79 & 32 & & 114 & 14 & \\
\hline Choline & 222 & 24 & 189 & 24 & & 251 & 34 & \\
\hline Citrate & 773 & 116 & 597 & 63 & & 1076 & 169 & * \\
\hline Creatine & 817 & 40 & 839 & 132 & & 891 & 97 & \\
\hline Dimethylamine & 13 & 1 & 11 & 2 & & 10 & 1 & \\
\hline Ethanol & 220 & 31 & 146 & 34 & & 181 & 13 & \\
\hline Formate & 174 & 23 & 155 & 10 & & 165 & 27 & \\
\hline Fumarate & 20 & 3 & 12 & 4 & & 33 & 7 & * \\
\hline Glucose & 29159 & 4531 & 23873 & 3222 & & 33088 & 2902 & \\
\hline Glutamate & 337 & 37 & 256 & 37 & & 334 & 27 & \\
\hline Glutamine & 1595 & 239 & 1019 & 125 & & 1701 & 147 & * \\
\hline Glycerol & 2638 & 238 & 2366 & 377 & & 3010 & 469 & \\
\hline Glycine & 1400 & 138 & 893 & 130 & $\#$ & 1195 & 102 & \\
\hline Histidine & 248 & 27 & 169 & 32 & & 218 & 17 & \\
\hline Isobutyrate & 57 & 10 & 30 & 4 & $\#$ & 49 & 6 & \\
\hline Isoleucine & 393 & 59 & 244 & 37 & & 286 & 26 & \\
\hline Lactate & 19808 & 1196 & 13878 & 1491 & $\#$ & 16821 & 1797 & \\
\hline Leucine & 486 & 76 & 337 & 52 & & 369 & 39 & \\
\hline Lysine & 744 & 49 & 792 & 100 & & 737 & 81 & \\
\hline Malonate & 89 & 13 & 80 & 9 & & 98 & 10 & \\
\hline Mannose & 106 & 15 & 136 & 28 & & 251 & 35 & * \\
\hline Methionine & 341 & 34 & 212 & 34 & $\#$ & 207 & 18 & \\
\hline O-Acetylcarnitine & 45 & 10 & 39 & 5 & & 105 & 17 & $* *$ \\
\hline Phenylalanine & 235 & 20 & 179 & 27 & & 176 & 11 & \\
\hline Proline & 627 & 47 & 337 & 66 & \#\# & 270 & 41 & \\
\hline Pyruvate & 480 & 23 & 261 & 32 & $\#$ & 471 & 65 & * \\
\hline Serine & 740 & 67 & 449 & 64 & \#\# & 524 & 29 & \\
\hline Succinate & 44 & 9 & 44 & 5 & & 85 & 20 & \\
\hline Taurine & 2811 & 217 & 2860 & 452 & & 3498 & 299 & \\
\hline Threonine & 938 & 85 & 636 & 117 & & 631 & 34 & \\
\hline Trimethylamine $\mathrm{N}$-oxide & 200 & 29 & 143 & 41 & & 134 & 24 & \\
\hline Tryptophan & 83 & 7 & 65 & 8 & & 52 & 11 & \\
\hline Tyrosine & 252 & 19 & 171 & 23 & $\#$ & 168 & 8 & \\
\hline Urocanate & 0 & 0 & 32 & 11 & $\#$ & 44 & 5 & \\
\hline Valine & 955 & 136 & 598 & 93 & & 610 & & \\
\hline
\end{tabular}

$\# p<0.05, \# \# p<0.01$ immobilized vs. intact; ${ }^{*} p<0.05,{ }^{* *} p<0.01$ GLPG0492-treated vs. CTL; Data are expressed as mean concentrations $(\mu M) \pm$ SEM. 


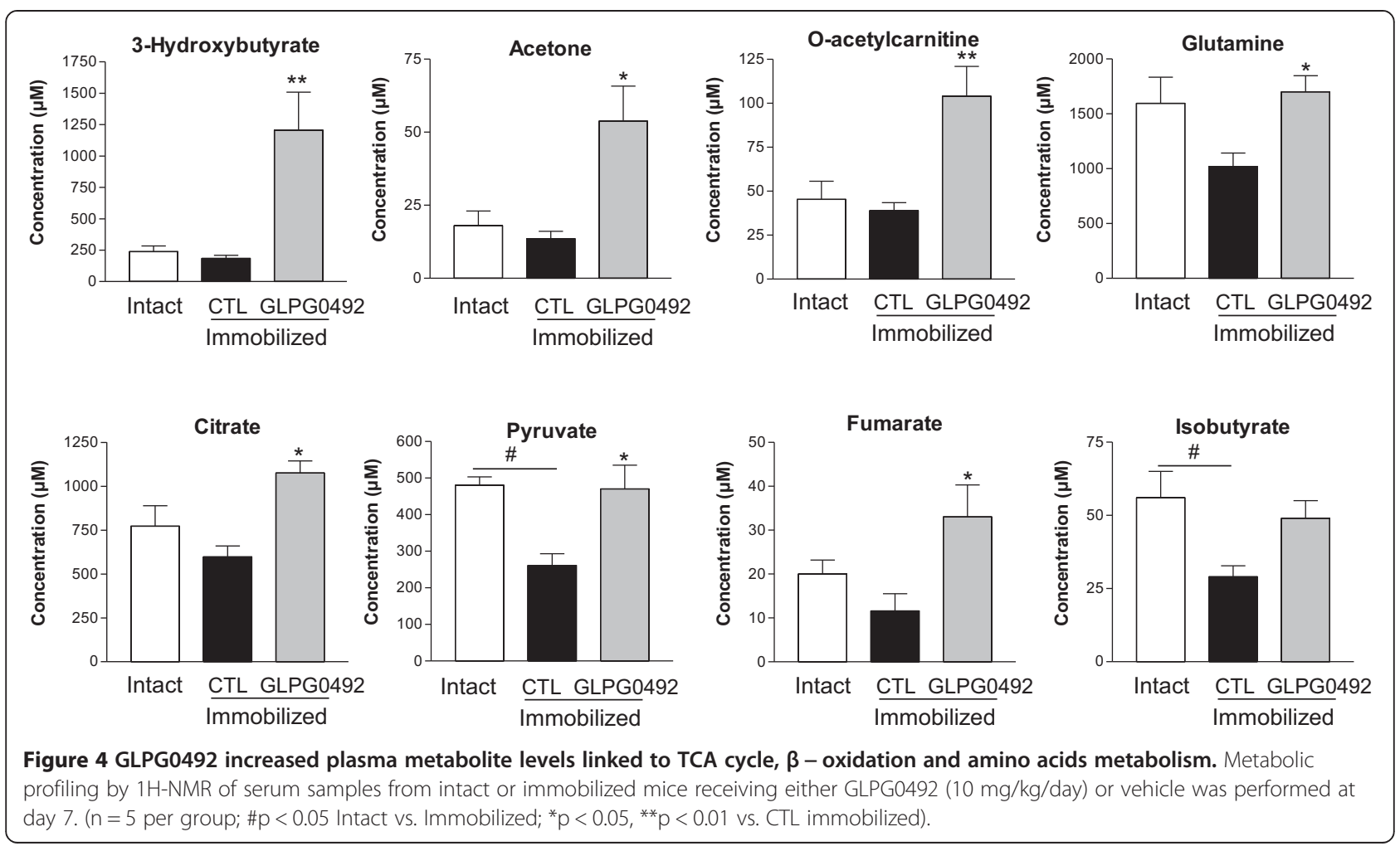

establish this cross-talk in the atrophied muscle. Nevertheless, the inhibition of MurF1 expression suggests that GLPG0492 and TP prevent muscle atrophy, by slowingdown protein catabolism.

Interestingly, both treatments failed to regulate markers of autophagy as demonstrated by the lack of LC3 gene regulation despite a significant induction following immobilization for 7 days (Figure 3A). While the role of TNF $\alpha$ and other cytokines in disuse-induced atrophy remain unclear [62], we found a strong up-regulation of IL1 $\beta$ mRNA levels following immobilization in line with previous results [39]. This induction was completely abolished by treatment with both TP and GLPG0492 (Figure 3) suggesting again a potential cross-talk between NFKB and AR pathways at the transcriptional level. FoxOs have been identified as the major transcription factors controlling the balance between protein catabolism and anabolism [4]. FoxO1 expression is significantly up-regulated in our model of hindlimb immobilization (Figure 3A) in line with previous reports $[5,8,15]$. This induction is also significantly repressed by both GLPG0492 and TP treatments suggesting that AR activation may prevent muscle-atrophy by negatively interfering with this transcriptional pathway leading ultimately to a regulation of protein homeostasis in this tissue. It is noteworthy that FoxO signaling has been shown to be repressed by PGC-1 $\alpha$ [19] whose expression was found to be increased in response to GLPG0492 and TP to a lesser extent (Figure 3A). Taken together, these results indicate that GLPG0492 minimizes muscle atrophy by antagonizing the key transcriptional pathways governing both anabolic and catabolic response.

Results obtained in the focused metabolomic study points to a modulation of cellular bioenergetic processes linked to mitochondrial function and perhaps to ketogenesis (Table 3; Figure 4). These results are quite consistent with the observed up-regulation of PGC- $1 \alpha$ gene expression and may reflect the overall cellular state upon chronic treatment with GLPG0492 in this hindlimb immobilization model. In addition, the GLPG0492 metabolomic signature is somehow comparable to signatures previously related to moderate exercise in human plasma [50,52]. Further studies will be required to fully demonstrate that these alterations of the plasma metabolome are mainly reflecting changes in skeletal muscle physiology. More studies are still required to investigate the possibility that muscle protein synthesis could be assessed as a plasma biomarker in human cachexia. In a recent study, Glover and coworkers have measured markers of protein breakdown and oxidative stress in muscles of subjects who underwent 14 days of knee-brace-mediated immobilization. These static measures of breakdown and oxidative modifications suggested that a small increase in protein ubiquitination occurs early ( 2 days post-immobilization), but is not sustained during the later phase (after 14 days) of muscle atrophy in humans, suggesting that these pathways are not playing a major role in simple disuse-induced atrophic loss of 
protein mass [63]. Other groups have hypothesized that the loss of muscle mass results from a reduction in the rate of protein synthesis. Thus, the normal diurnal fasted-tofed cycle of protein balance is disrupted and, as a consequence proteolysis becomes dominant but is not enhanced [63]. Nevertheless, this metabolomics signature might be considered as a bona fide biomarker of target engagement in future clinical studies and may represent an alternative to the measurement of the muscle fractional synthetic rate as a mechanistic endpoint which remains quite challenging to implement in phase 1 studies conducted in young healthy volunteers [64].

\section{Conclusion}

GLPG0492 was found as efficacious as TP at reducing muscle loss in the hindlimb immobilization model. These effects were achieved without any significant androgenic effects on sexual tissue (Table 1, Figure 1C). Collectively, these results unveil the potential of GLPG0492, a non-steroidal SARM, as treatment for musculo-skeletal diseases such as disuse-induced loss of muscle mass (e.g. coma, paralysis, hospitalization, limb immobilization).

\section{Competing interests}

All authors are employees of Galapagos. GLPG0492 was synthesized by the medicinal chemistry department at Galapagos.

\section{Authors' contributions}

$M A, R B, L L, P C L, P D$ and $F N$ designed and interpreted study's results. $M A, L L$, $\mathrm{DM}, \mathrm{DMi}$ and CC performed most of the experiments and analyzed the data. PCL \& PD drafted the manuscript. All authors read and approved the final manuscript.

\section{Acknowledgments}

The authors would like to thank François Gendrot, Isabelle Renoult, Christelle David, and Laëtitia Perret for excellent technical assistance and Dr. Virginie Gaillard for statistical analyses.

Received: 26 February 2014 Accepted: 27 August 2014

Published: 3 September 2014

\section{References}

1. Kamel HK: Sarcopenia and aging. Nutr Rev 2003, 61(5 Pt 1):157-167.

2. Argiles JM, Busquets S, Felipe A, Lopez-Soriano FJ: Molecular mechanisms involved in muscle wasting in cancer and ageing: cachexia versus sarcopenia. Int J Biochem Cell Biol 2005, 37(5):1084-1104.

3. Evans WJ: Skeletal muscle loss: cachexia, sarcopenia, and inactivity. Am J Clin Nutr 2010, 91(4):1123S-1127S.

4. Sandri M: Signaling in muscle atrophy and hypertrophy. Physiology (Bethesda) 2008, 23:160-170.

5. Sacheck JM, Hyatt JP, Raffaello A, Jagoe RT, Roy RR, Edgerton VR, Lecker SH, Goldberg AL: Rapid disuse and denervation atrophy involve transcriptional changes similar to those of muscle wasting during systemic diseases. Faseb J 2007, 21(1):140-155.

6. Bodine SC, Latres E, Baumhueter S, Lai VK, Nunez L, Clarke BA, Poueymirou WT, Panaro FJ, Na E, Dharmarajan K, Pan ZQ, Valenzuela DM, DeChiara TM, Stitt TN, Yancopoulos GD, Glass DJ: Identification of ubiquitin ligases required for skeletal muscle atrophy. Science 2001, 294(5547):1704-1708.

7. Gomes MD, Lecker SH, Jagoe RT, Navon A, Goldberg AL: Atrogin-1, a muscle-specific F-box protein highly expressed during muscle atrophy. Proc Natl Acad Sci U S A 2001, 98(25):14440-14445.

8. Sandri M, Sandri C, Gilbert A, Skurk C, Calabria E, Picard A, Walsh K, Schiaffino S, Lecker SH, Goldberg AL: Foxo transcription factors induce the atrophy-related ubiquitin ligase atrogin-1 and cause skeletal muscle atrophy. Cell 2004, 117(3):399-412.

9. Clarke BA, Drujan D, Willis MS, Murphy LO, Corpina RA, Burova E, Rakhilin SV, Stitt TN, Patterson C, Latres E, Glass DJ: The E3 Ligase MuRF1 degrades myosin heavy chain protein in dexamethasone-treated skeletal muscle. Cell Metab 2007, 6(5):376-385.

10. Fielitz J, Kim MS, Shelton JM, Latif S, Spencer JA, Glass DJ, Richardson JA, Bassel-Duby R, Olson EN: Myosin accumulation and striated muscle myopathy result from the loss of muscle RING finger 1 and 3. I Clin Invest 2007, 117(9):2486-2495.

11. Li HH, Kedar V, Zhang C, McDonough H, Arya R, Wang DZ, Patterson C: Atrogin-1/muscle atrophy F-box inhibits calcineurin-dependent cardiac hypertrophy by participating in an SCF ubiquitin ligase complex. I Clin Invest 2004, 114(8):1058-1071.

12. Tintignac LA, Lagirand J, Batonnet S, Sirri V, Leibovitch MP, Leibovitch SA: Degradation of MyoD mediated by the SCF (MAFbx) ubiquitin ligase. J Biol Chem 2005, 280(4):2847-2856.

13. Mizushima N, Yamamoto A, Matsui M, Yoshimori T, Ohsumi Y: In vivo analysis of autophagy in response to nutrient starvation using transgenic mice expressing a fluorescent autophagosome marker. Mol Biol Cell 2004, 15(3):1101-1111.

14. Mordier S, Deval C, Bechet D, Tassa A, Ferrara M: Leucine limitation induces autophagy and activation of lysosome-dependent proteolysis in C2C12 myotubes through a mammalian target of rapamycinindependent signaling pathway. J Biol Chem 2000, 275(38):29900-29906.

15. Kamei Y, Miura S, Suzuki M, Kai Y, Mizukami J, Taniguchi T, Mochida K, Hata T, Matsuda J, Aburatani H, Nishino I, Ezaki O: Skeletal muscle FOXO1 (FKHR) transgenic mice have less skeletal muscle mass, down-regulated Type I (slow twitch/red muscle) fiber genes, and impaired glycemic control. J Biol Chem 2004, 279(39):41114-41123.

16. Southgate RJ, Neill B, Prelovsek O, El-Osta A, Kamei Y, Miura S, Ezaki O, McLoughlin TJ, Zhang W, Unterman TG, Febbraio MA: FOXO1 regulates the expression of $4 \mathrm{E}-\mathrm{BP} 1$ and inhibits mTOR signaling in mammalian skeletal muscle. J Biol Chem 2007, 282(29):21176-21186.

17. Abadi A, Glover El, Isfort RJ, Raha S, Safdar A, Yasuda N, Kaczor JJ, Melov S, Hubbard A, Qu X, Phillips SM, Tarnopolsky M: Limb immobilization induces a coordinate down-regulation of mitochondrial and other metabolic pathways in men and women. PLoS One 2009, 4(8):e6518.

18. Lin J, Wu H, Tarr PT, Zhang CY, Wu Z, Boss O, Michael LF, Puigserver P, Isotani E, Olson EN, Lowell BB, Bassel-Duby R, Spiegelman BM: Transcriptional co-activator PGC-1 alpha drives the formation of slow-twitch muscle fibres. Nature 2002, 418(6899):797-801.

19. Sandri M, Lin J, Handschin C, Yang W, Arany ZP, Lecker SH, Goldberg AL, Spiegelman BM: PGC-1alpha protects skeletal muscle from atrophy by suppressing FoxO3 action and atrophy-specific gene transcription. Proc Natl Acad Sci U S A 2006, 103(44):16260-16265.

20. Bhasin S, Storer TW, Berman N, Callegari C, Clevenger B, Phillips J, Bunnell TJ, Tricker R, Shirazi A, Casaburi R: The effects of supraphysiologic doses of testosterone on muscle size and strength in normal men. N Engl J Med 1996, 335(1):1-7.

21. Storer TW, Magliano L, Woodhouse L, Lee ML, Dzekov C, Dzekov J, Casaburi $\mathrm{R}$, Bhasin S: Testosterone dose-dependently increases maximal voluntary strength and leg power, but does not affect fatigability or specific tension. J Clin Endocrinol Metab 2003, 88(4):1478-1485.

22. Evans RM: The steroid and thyroid hormone receptor superfamily. Science 1988, 240(4854):889-895.

23. Narayanan R, Coss CC, Yepuru M, Kearbey JD, Miller DD, Dalton JT: Steroidal androgens and nonsteroidal, tissue-selective androgen receptor modulator, $\mathrm{S}-22$, regulate androgen receptor function through distinct genomic and nongenomic signaling pathways. Mol Endocrinol 2008, 22(11):2448-2465.

24. Bhasin S, Calof OM, Storer TW, Lee ML, Mazer NA, Jasuja R, Montori VM, Gao W, Dalton JT: Drug insight: Testosterone and selective androgen receptor modulators as anabolic therapies for chronic illness and aging. Nat Clin Pract Endocrinol Metab 2006, 2(3):146-159.

25. Narayanan R, Mohler ML, Bohl CE, Miller DD, Dalton JT: Selective androgen receptor modulators in preclinical and clinical development. Nucl Recept Signal 2008, 6:e010.

26. Nique F, Hebbe S, Triballeau N, Peixoto C, Lefrançois JM, Jary H, Alvey L, Manioc M, Housseman C, Klaassen H, Van Beeck K, Guédin D, Namour F, Minet D, Van der Aar E, Feyen J, Fletcher S, Blanqué R, Robin-Jagerschmidt C, Deprez P: Identification of a 4-(hydroxymethyl) diarylhydantoin as a 
selective androgen receptor modulator. Journal of medicinal chemistry 2012, 55(19):8236-8247.

27. Nique F, Hebbe S, Peixoto C, Annoot D, Lefrançois JM, Duval E, Michoux L, Triballeau N, Lemoullec JM, Mollat $P$, Thauvin M, Prangé T, Minet $D$, Clément-Lacroix P, Robin-Jagerschmidt C, Fleury D, Guédin D, Deprez P: Discovery of diarylhydantoins as new selective androgen receptor modulators. J Med Chem 2012, 55(19):8225-8235.

28. Okamoto T, Torii S, Machida S: Differential gene expression of musclespecific ubiquitin ligase MAFbx/Atrogin-1 and MuRF1 in response to immobilization-induced atrophy of slow-twitch and fast-twitch muscles. J Physiol Sci 2011, 61(6):537-546.

29. Delerive P, Galardi CM, Bisi JE, Nicodeme E, Goodwin B: Identification of liver receptor homolog-1 as a novel regulator of apolipoprotein Al gene transcription. Mol Endocrinol 2004, 18(10):2378-2387.

30. Ruas JL, White JP, Rao RR, Kleiner S, Brannan KT, Harrison BC, Greene NP, Wu J, Estall JL, Irving BA, Lanza IR, Rasbach KA, Okutsu M, Nair KS, Yan Z, Leinwand LA, Spiegelman BM: A PGC-1a isoform induced by resistance training regulates skeletal muscle hypertrophy. Cell 2012, 151(6):1319-1331.

31. Midrio M: The denervated muscle: facts and hypotheses. A historical review. Eur J Appl Physiol 2006, 98(1):1-21.

32. Morey-Holton ER, Globus RK: Hindlimb unloading rodent model: technical aspects. J Appl Physiol 2002, 92(4):1367-1377.

33. Frimel TN, Kapadia F, Gaidosh GS, Li Y, Walter GA, Vandenborne K: A model of muscle atrophy using cast immobilization in mice. Muscle Nerve 2005, 32(5):672-674.

34. Jones A, Hwang DJ, Narayanan R, Miller DD, Dalton JT: Effects of a novel selective androgen receptor modulator on dexamethasone-induced and hypogonadism-induced muscle atrophy. Endocrinology 2010, 151(8):3706-3719

35. Zhao W, Pan J, Zhao Z, Wu Y, Bauman WA, Cardozo CP: Testosterone protects against dexamethasone-induced muscle atrophy, protein degradation and MAFbx upregulation. J Steroid Biochem Mol Biol 2008, 110(1-2):125-129.

36. Caron AZ, Haroun S, Leblanc E, Trensz F, Guindi C, Amrani A, Grenier G: The proteasome inhibitor MG132 reduces immobilization-induced skeletal muscle atrophy in mice. BMC Musculoskelet Disord 2011, 12:185.

37. Machida S, Booth FW: Changes in signalling molecule levels in 10-day hindlimb immobilized rat muscles. Acta Physio/ Scand 2005, 183(2):171-179.

38. Sinha-Hikim I, Artaza J, Woodhouse L, Gonzalez-Cadavid N, Singh AB, Lee Ml, Storer TW, Casaburi R, Shen R, Bhasin S: Testosterone-induced increase in muscle size in healthy young men is associated with muscle fiber hypertrophy. Am J Physiol Endocrinol Metab 2002, 283(1):E154-E164.

39. Caron AZ, Drouin G, Desrosiers J, Trensz F, Grenier G: A novel hindlimb immobilization procedure for studying skeletal muscle atrophy and recovery in mouse. J Appl Physiol 2009, 106(6):2049-2059.

40. Urso ML, Scrimgeour AG, Chen YW, Thompson PD, Clarkson PM: Analysis of human skeletal muscle after $48 \mathrm{~h}$ immobilization reveals alterations in mRNA and protein for extracellular matrix components. J Appl Physiol 2006, 101(4):1136-1148.

41. Hyatt JP, Roy RR, Baldwin KM, Edgerton VR: Nerve activity-independent regulation of skeletal muscle atrophy: role of $\mathrm{MyoD}$ and myogenin in satellite cells and myonuclei. Am J Physiol Cell Physiol 2003, 285(5):C1161-C1173.

42. Argiles JM, Lopez-Soriano FJ: The role of cytokines in cancer cachexia. Med Res Rev 1999, 19(3):223-24843.

43. Arany Z, Wagner BK, Ma Y, Chinsomboon J, Laznik D, Spiegelman BM: Gene expression-based screening identifies microtubule inhibitors as inducers of PGC-1alpha and oxidative phosphorylation. Proc Natl Acad Sci U S A 2008, 105(12):4721-4726.

44. Booth FW, Seider MJ: Early change in skeletal muscle protein synthesis after limb immobilization of rats. J App/ Physio/ 1979, 47:974-977.

45. Busquets S, Alvarez B, Llovera M, Agell N, Lopez-Soriano FJ, Argiles JM: Branched-chain amino acids inhibit proteolysis in rat skeletal muscle: mechanisms involved. J Cell Physiol 2000, 184(3):380-384.

46. Kobayashi H, Kato H, Hirabayashi Y, Murakami H, Suzuki H: Modulations of muscle protein metabolism by branched-chain amino acids in normal and muscle-atrophying rats. J Nutr 2006, 136(1 Suppl):234S-236S.

47. Bonetto A, Penna F, Minero VG, Reffo P, Costamagna D, Bonelli G, Baccino FM, Costelli P: Glutamine prevents myostatin hyperexpression and protein hypercatabolism induced in C2C12 myotubes by tumor necrosis factor-alpha. Amino Acids 2011, 40(2):585-594.
48. Maki T, Yamamoto D, Nakanishi S, lida K, lguchi G, Takahashi Y, Kaji H, Chihara K, Okimura Y: Branched-chain amino acids reduce hindlimb suspension-induced muscle atrophy and protein levels of atrogin-1 and MuRF1 in rats. Nutr Res 2012, 32(9):676-683.

49. Mirza KA, Pereira SL, Voss AC, Tisdale MJ: Comparison of the anticatabolic effects of leucine and Ca- $\beta$-hydroxy- $\beta$-methylbutyrate in experimental models of cancer cachexia. Nutrition 2014, 30(7-8):807-813.

50. Lewis GD, Farrell L, Wood MJ, Martinovic M, Arany Z, Rowe GC, Souza A, Cheng S, McCabe EL, Yang E, Shi X, Deo R, Roth FP, Asnani A, Rhee EP, Systrom DM, Semigran MJ, Vasan RS, Carr SA, Wang TJ, Sabatine MS, Clish CB, Gerszten RE: Metabolic signatures of exercise in human plasma. Sci Transl Med 2010, 2(33):33ra37.

51. Vega GL, Clarenbach JJ, Dunn F, Grundy SM: Oxandrolone enhances hepatic ketogenesis in adult men. J Investig Med 2008, 56(7):920-924.

52. Lehmann $R$, Zhao $X$, Weigert $C$, Simon $P$, Fehrenbach $E$, Fritsche J, Machann J, Schick F, Wang J, Hoene M, Schleicher ED, Häring HU, Xu G, Niess AM: Medium chain acylcarnitines dominate the metabolite pattern in humans under moderate intensity exercise and support lipid oxidation. PloS One 2010, 5(7):e11519.

53. Basaria S, Collins L, Dillon EL, Orwoll K, Storer TW, Miciek R, Ulloor J, Zhang A, Eder R, Zientek H, Gordon G, Kazmi S, Sheffield-Moore M, Bhasin S: The Safety, Pharmacokinetics, and Effects of LGD-4033, a novel nonsteroidal oral, selective androgen receptor modulator, in healthy young men. J Gerontol A Biol Sci Med Sci 2013, 68(1):87-95.

54. Dalton JT, Barnette KG, Bohl CE, Hancock ML, Rodriguez D, Dodson ST, Morton RA, Steiner MS: The selective androgen receptor modulator GTx-024 (enobosarm) improves lean body mass and physical function in healthy elderly men and postmenopausal women: results of a double-blind, placebo-controlled phase II trial. J Cachexia Sarcopenia Muscle 2011, 2(3):153-161.

55. Dubois V, Laurent M, Boonen S, Vanderschueren D, Claessens F: Androgens and skeletal muscle: cellular and molecular action mechanisms underlying the anabolic actions. Cell Mol Life Sci 2011, 69(10):1651-1667.

56. Chambon C, Duteil D, Vignaud A, Ferry A, Messaddeq N, Malivindi R, Kato S, Chambon $\mathrm{P}$, Metzger D: Myocytic androgen receptor controls the strength but not the mass of limb muscles. Proc Natl Acad Sci U S A 2010, 107(32):14327-14332

57. MacLean HE, Chiu WS, Notini AJ, Axell AM, Davey RA, McManus JF, Ma C, Plant DR, Lynch GS, Zajac JD: Impaired skeletal muscle development and function in male, but not female, genomic androgen receptor knockout mice. Faseb J 2008, 22(8):2676-2689.

58. Lee NK, Skinner JP, Zajac JD, MacLean HE: Ornithine decarboxylase is upregulated by the androgen receptor in skeletal muscle and regulates myoblast proliferation. Am J Physiol Endocrinol Metab 2011, 301(1):E172-E179.

59. Cai D, Frantz JD, Tawa NE Jr, Melendez PA, Oh BC, Lidov HG, Hasselgren PO, Frontera WR, Lee J, Glass DJ, Shoelson SE: IKKbeta/NF-kappaB activation causes severe muscle wasting in mice. Cell 2004, 119(2):285-298.

60. Hunter RB, Kandarian SC: Disruption of either the Nfkb1 or the Bcl3 gene inhibits skeletal muscle atrophy. J Clin Invest 2004, 114(10):1504-1511.

61. Hunter RB, Stevenson E, Koncarevic A, Mitchell-Felton H, Essig DA, Kandarian SC: Activation of an alternative NF-kappaB pathway in skeletal muscle during disuse atrophy. Faseb J 2002, 16(6):529-538.

62. Moldawer LL, Svaninger G, Gelin J, Lundholm KG: Interleukin 1 and tumor necrosis factor do not regulate protein balance in skeletal muscle. Am J Physiol 1987, 253(6 Pt 1):C766-C773.

63. Phillips SM, Glover El, Rennie MJ: Alterations of protein turnover underlying disuse atrophy in human skeletal muscle. J Appl Physiol (1985) 2009, 107(3):645-654.

64. Glover El, Yasuda N, Tarnopolsky MA, Abadi A, Phillips SM: Little change in markers of protein breakdown and oxidative stress in humans in immobilization-induced skeletal muscle atrophy. Appl Physiol Nutr Metab 2010, 35(2):125-133.

doi:10.1186/1471-2474-15-291

Cite this article as: Blanqué et al.: Characterization of GLPG0492, a

selective androgen receptor modulator, in a mouse model of hindlimb immobilization. BMC Musculoskeletal Disorders 2014 15:291. 